\title{
Nurse Practitioner and Physician Preceptors Perceptions of Student Nurse Practitioner Training and Practice: Expectations, Comparison with Medical Students and Faculty Experience
}

\author{
Eileen R. Giardino ${ }^{1}$ and Angelo P. Giardino ${ }^{2, *}$ \\ ${ }^{1}$ The University of Texas Health Science Center - Houston School of Nursing, 6901 Bertner Ave, Houston, TX 77030, \\ USA \\ ${ }^{2}$ Texas Children's Health Plan, Clinical Professor, Pediatrics, Baylor College of Medicine, Adjunct Professor, The Uni- \\ versity of Texas School of Nursing at Houston, 2450 Holcombe, Suite 34L, Houston, Texas 77021, USA
}

\begin{abstract}
Purpose: To determine the perceptions of nurse practitioner and physician preceptors towards student nurse practitioners focusing specifically on what preceptors expect from student nurse practitioners at the beginning and at the end of the clinical training experience, how each views the student nurse practitioners as compared to medical students at various years in medical school, and the preceptors own faculty experience.

Results: The overall adjusted response rate for the survey was 58\% (94/161). Nurse practitioner and physician preceptors found student nurse practitioners to be at an expected level of practice when starting clinical experiences in a primary care setting in these areas: completing a history, adjusting med doses, diagnosing common problems, determining treatment meds and teaching about home care responsibilities. Nurse practitioner and physician preceptors thought student nurse practitioners were weaker than expected in the areas of generating differential diagnoses and prioritizing differentials. Nurse practitioner and physician preceptors differed in their comparison of beginning student nurse practitioners to medical students in different years of training with physician preceptors viewing student nurse practitioners as comparable to first and second year medical students where as nurse practitioner preceptors viewed them as comparable to third and fourth year medical students.

Conclusion: Remarkable similarity exists among nurse practitioner and physician preceptors around expectations for clinical skill development for their student nurse practitioner trainees. Some differences do exist around views of how student nurse practitioner trainees compare in the clinical setting to medical students in different years of medical school. Regarding faculty experience each group of preceptors values their precepting experience. Enhanced orientation and faculty development efforts may be of value in clarifying roles and responsibilities among nurse practitioner and physician preceptors when working with student nurse practitioners.
\end{abstract}

Keywords: Preceptor, nurse practitioner, student nurse practitioner training.

\section{INTRODUCTION}

Nurse practitioners have become a vital part of health care delivery with a burgeoning number of graduate programs in the United States. Primary care nurse practitioners work collaboratively with physicians and independently in nurse practitioner run practices to provide care to patients in a variety of clinical settings [1]. The estimated expanded coverage to approximately 30 million more people in the US by 2014 due to the 2010 Patient Protection and Affordable Care Act raises concerns about the shortage of primary care physicians needed to care for the increasing numbers of people who will require primary care visits $[2,3]$. The anticipated shortfall in the number of available primary care

*Address correspondence to this author at the Texas Children's Health Plan, Clinical Professor, Pediatrics, Baylor College of Medicine, Adjunct Professor, The University of Texas School of Nursing at Houston, 2450 Holcombe, Suite 34L, Texas 77021, Houston; Tel: 832-828-1216;

Fax: 832-825-8765; E-mail: apgiardi@texaschildrens.org providers is one reason that advanced practice nurses, i.e., nurse practitioners, are increasingly viewed as a likely source of highly trained health care providers who could provide needed primary care in a high quality manner. Of utmost importance in the educational process of nurse practitioner students is the supervision and training provided by physician and nurse practitioner clinicians who give freely of their time to educate nurse practitioner students in their offices and clinics. Every nurse practitioner program relies on preceptors to guide the student nurse practitioners in their clinical practice and teach students clinical skills necessary to evaluate, diagnose and treat patients. With an increasing need for primary care nurse practitioners, it is important to understand what physicians and nurse practitioners who educate nurse practitioner students in the clinical setting believe about their role as a preceptor, so that nurse practitioner programs know how best to recruit and retain excellent preceptors. 
Physician and nurse practitioner preceptors are a valuable resource to every nurse practitioner program and essential to the strength and viability of a nurse practitioner program. Preceptors volunteer their time to teach students essential clinical skills and evaluate student competence and performance. Since preceptors play an essential role in nurse practitioner development, it is important that nurse practitioner programs understand what preceptors expect from students and the schools that rely on their guidance and input. In order to recruit and retain both nurse practitioner and physician preceptors, it is essential to understand preceptor needs and address concerns that stem from providing the student training experience.

This research study describes the perceptions of nurse practitioner and physician preceptors regarding what they expect when they precept students at their clinical sites both at the beginning and at the conclusion of that training experience, as well as preceptor perceptions around teaching approaches to student nurse practitioners and medical students in primary care settings. The purpose of this study was to determine what expectations nurse practitioner and physician preceptors have for student nurse practitioners' learning; differences in how nurse practitioner preceptors and physician preceptors view student nurse practitioners in their primary care setting; reasons preceptors work with student nurse practitioners; and, preceptor expectations of what the program should provide to them as faculty preceptors.

\section{BACKGROUND/REVIEW OF LITERATURE}

Preceptors play an integral role in the development of the student nurse practitioners in clinical sites where students learn primary care skills. The preceptor guides the student transition from registered nurse to advanced practice nurse and guides in the art and skill of diagnosis and medical treatment of patients in the primary care setting [4-8]. While both nurse practitioner and physicians $[9,10]$ precept student nurse practitioners, each clinician has a distinct professional and educational background that may focus on different expectations of what the student should know and accomplish in the clinical setting [11]. Davis, Sawin and Dunn studied teaching strategies used by expert preceptors in working with students in the clinical setting. They identified different strategies used with students at varying levels and classified different preceptor styles according to how they dealt with students [11].

Physicians may interact with nurse practitioner students differently than how nurse practitioners approach them to accomplish program goals and role socialization. As student nurse practitioners experience clinical training along with medical students and physician assistant students, physicians may be unclear as to what the expectations of the nurse practitioner program are, at what point in the educational process the student nurse practitioner is, and what to expect of the student's clinical knowledge and skills [12].

Lyon and Peach studied primary care provider's views of precepting nurse practitioner students [13]. They found that preceptors were satisfied with precepting, but faced factors such as liability concerns and conflicts between student's educational needs and practice expectations to increase provider productivity as barriers to the precepting experience [13]. Hayes described how first time preceptors may face issues they are unaware of or how they may feel initially unprepared for when precepting nurse practitioner students. The authors reviewed what the preceptor role involves, possible evaluation methods, and how to create a supporting environment for students [6].

Some studies have addressed what responsibilities the nurse practitioner program and its faculty have towards the student in the clinical setting. A study by Brooks and Niederhauser found that a majority of preceptors expected two site visits each semester and that program faculty members should observe their students with patient visits [14].

Prior studies have addressed preceptor issues such as students' perception of the mentor's ability, [15] teaching strategies used by nurse practitioner preceptors [11], and the relationship between Student nurse practitioners ' perceptions of mentoring in relation to their feelings of selfefficacy [7, 8]. A study of nurse practitioner students' perceptions of preceptor mentoring and student self-efficacy found a modest correlation between the two that translates into a positive role with students who choose preceptors they know and admire. A longer term commitment with a preceptor has positive effects on the overall relationship [8].

Studies have addressed teaching strategies preceptors can use to maximize learning opportunities that promote transition to professional practice [16]. Preceptors report greater self-confidence in rating students when they have had training in the precepting process [16].

Recommendations from preceptor studies are helpful in strengthening the approaches that preceptors can take to work with nurse practitioner students to enhance clinical learning. Nursing literature gives insight into approaches that mentors can take to be more effective in the role of clinical teaching and role socialization [6]. However, little is found in nursing literature concerning differences or similarities between nurse practitioner preceptors and physician preceptors in precepting styles and approaches.

\section{PURPOSE OF THE STUDY}

The purpose of this study is to determine: what expectations nurse practitioner preceptors and physician preceptors have for student nurse practitioners' performance during clinical training experiences; differences or similarities in how nurse practitioner preceptors and physician preceptors view student nurse practitioners in a primary care setting especially as compared to medical students at in various years of medical school training; reasons preceptors work with student nurse practitioners; and, preceptor expectations of what the nurse practitioner program should provide to preceptors.

\section{METHODS}

This is a descriptive, non-experimental study that utilized a 98-item questionnaire that was developed by the investigators.

\section{Instrument}

The researchers developed a questionnaire to determine opinions of physician and nurse practitioners who oversee clinic training for student nurse practitioners in family nurse practitioner or adult nurse practitioner programs at an urban 
university in a large United States (US) Northeastern city. A pilot study of ten nursing faculty members reviewed questions for clarity and comprehension. The final 98 item questionnaire consisted of 12 major questions which each had multiple items that used either Likert type rating scales and yes/no type response formats. Additional seven items asked about respondent characteristics necessary for analysis. Because actually participating in the clinical care of a patient is fundamental to the teaching of clinical skills, four major questions on the questionnaire asked preceptors to consider 8 key skills necessary to complete a comprehensive primary care oriented health care evaluation. The eight observable clinical skills incorporated into the questions are listed below.

1) Completing history of present illness;

2) Completing appropriate physical examination for a specific problem;

3) Generating a differential diagnosis;

4) Prioritizing a diagnosis on the differential diagnosis;

5) Diagnosing common problems;

6) Adjusting medication doses;

7) Determining treatment medications;

8) Teaching patients about diagnosis and home care responsibilities.

\section{Sample}

The study sample consisted of the 172 nurse practitioners and physicians (both allopathic (MD) and osteopathic physicians (DO)) who participated as preceptors for nurse practitioner students enrolled in the adult or family nurse practitioner program at an urban, northeastern university in the United States of America. A total of 172 questionnaires were sent to the 64 physicians and 108 nurse practitioner preceptors listed as active preceptors at the urban university.

\section{Data Collection Process}

A cover letter and survey questionnaire were mailed to 108 NP preceptors and 64 physician preceptors who were on the list of preceptors at the university. Each subject received a stamped, addressed return envelope. The survey was sent out for total of three (3) rounds to those who had not responded to the first or second mailing. The protocol for the survey was reviewed and approved by the university's Institutional Review Board (IRB). The survey was confidential but not anonymous as each questionnaire was identified by a number to determine which preceptors had not answered. For each returned and completed questionnaire, the respondent's name was checked off on a master list and the questionnaire went into a pool of returned questionnaires where the respondent's name was not used or known in any aspect of the study results. Data analysis was done in aggregate and no specific preceptors were identified in the results.

\section{RESULTS}

\section{Response Rate and Respondent Characteristics}

Eleven surveys were returned due to incorrect addresses, 94 survey questionnaires were returned for an adjusted over- all response rate for the nurse practitioner and physician preceptors was 58\% (94/161). The overall nurse practitioner preceptors response rate was $64 \%$ while the physician preceptor response rate was $41 \%$. The data was analyzed using descriptive statistics. Seventy five percent of the respondents were female. The mean respondent age was 48 years. Twenty-seven percent $(n=25)$ of the respondents were physicians and 73\% $(n=69)$ were nurse practitioners, with 18 years as the mean number of years in clinical practice for both.

In order to promote a clear presentation of the results, the responses to the $90+$ item questionnaire are displayed around 3 content clusters, labeled A thru $\mathrm{C}$ that emerged during analysis. Clusters A and B , dealt with preceptor observation of the student's clinical skills, and as such questions related to those clusters sought information around the 8 clinical skills discussed above as well as comparisons to medical students and where appropriate to physicians assistant trainees. Clusters $\mathrm{C}$ was not clinically oriented and instead dealt with faculty related issues such as preceptors expectations of what the program should provide to the preceptors and reasons why they chose to accept the responsibility to precept student nurse practitioners. The three content clusters used for ease of presentation are listed below:

a Preceptor evaluation of nurse practitioner student clinical skills.

b Preceptor oversight of student nurse practitioners and comparison with medical students and physician assistant trainees.

c Preceptor faculty expectations and reasons for precepting student nurse practitioners.

\section{CONTENT CLUSTER A: PRECEPTOR EVALUA- TION OF NURSE PRACTITIONER STUDENT CLINICAL SKILLS}

Nurse practitioner and physician preceptors assessed the level of support they needed to give to the student at the beginning of a clinical rotation and at the end of the student's clinical training experience. Respondents rated the same eight (8) clinical skills listed in the Methods section above on a three (3) point scale of ranging from "little preceptor support", "minimal preceptor support" and "with much preceptor support”. See Table $\mathbf{1}$.

\section{At Beginning of Training Experience}

Nurse practitioner preceptors (NPP) and physician preceptors rated students similarly on the amount of support they expected to give the students to complete clinical skills at the beginning of a clinical experience. While a majority of nurse practitioner preceptors and physician preceptors (PP) felt that the student nurse practitioner needed little to minimal preceptor support to complete the history of present illness (HPI) [NPP 68\% vs. PPs 68\%] they differed on their views around the physical examination [NPP 65\% vs. PP $42 \%]$. A majority of NP and physician preceptors agreed that nurse practitioner students needed much support to generate differential diagnoses [NPP 71\%; vs. PP 69\%], prioritize differential diagnoses [NPP 70\% vs. PP 73\%], and to adjust treatment medications [NPP 67\% vs. PP 58\%]. The majority 
Table 1. Preceptor Support Level at Beginning and End of Clinical Experience

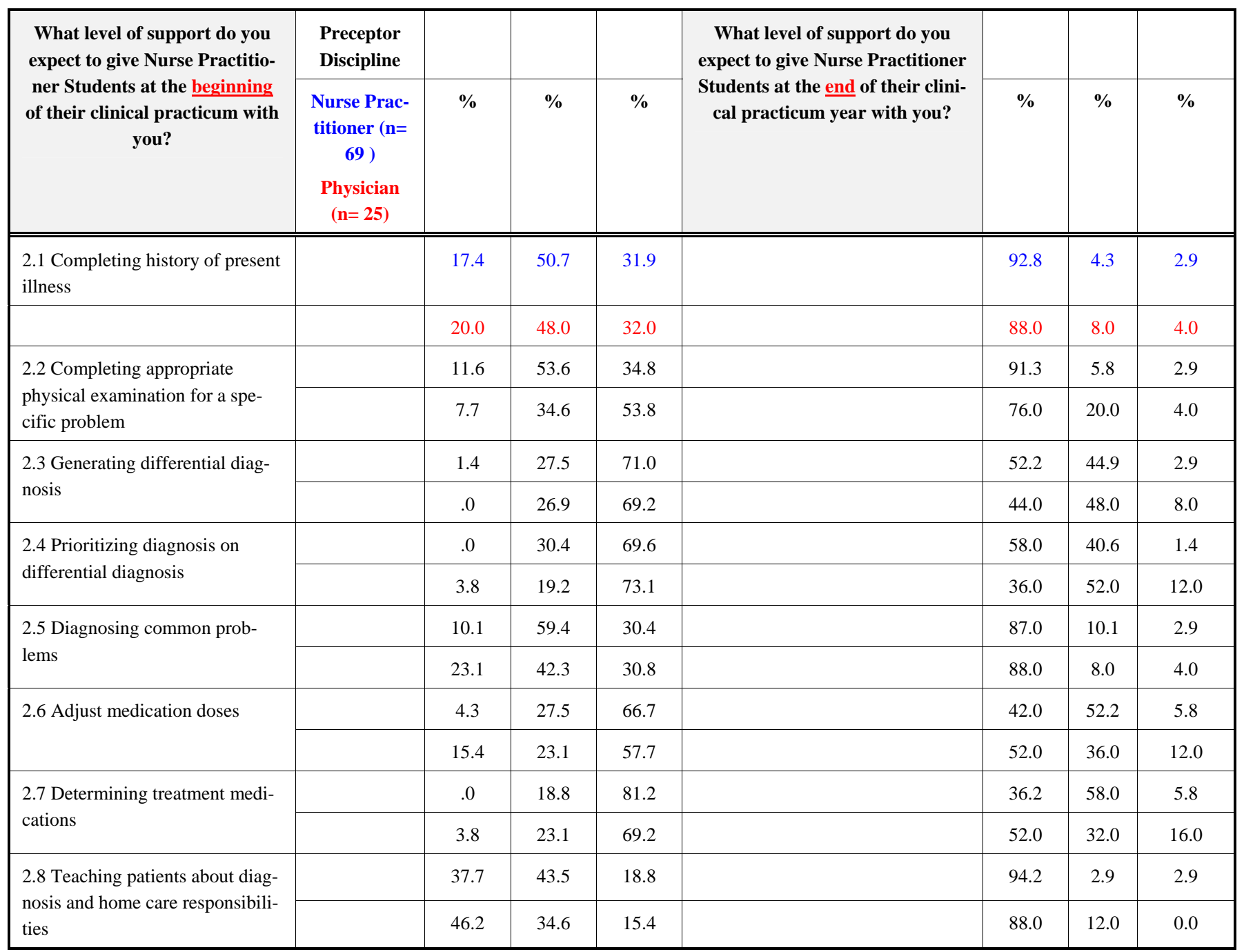

of physicians and nurse practitioner preceptors agreed that students needed minimal to little preceptor support to teach patients about diagnosis and home care responsibilities [NPP $81 \%$ vs. PP $81 \%]$.

\section{At End of Training Experience}

By the end of the student's clinical practicum year, a majority of nurse practitioner and physician preceptors reported that they expected to give students little support in completing a history of present illness [NPP 93\% vs. PP 88\%], and completing an appropriate physical examination (PE) for a specific problem [NPP 91\%vs.PP 76\%]. The majority of nurse practitioner and physician preceptors responded that they expected to give little to minimal support to generate a differential diagnosis [NPP 97\% vs. PP 92\%] by the end of the clinical experience. A majority of physicians [62\%] stated they expected to give nurse practitioner students minimal to much support to prioritize differential diagnoses, while the majority of NP preceptors [58\%] differed with their physician preceptor colleagues and stated they expected to give the NP students little support to prioritize differential diagnoses. A majority of both the nurse practitioner [94\%] and physician preceptors [77\%] reported that they expected to give NP students little to minimal support to adjust medication doses and to determine treatment medications by the end of the student's clinical year.

\section{CONTENT CLUSTER B: PRECEPTOR OVERSIGHT OF STUDENT NURSE PRACTITIONERS AND COM- PARISON WITH MEDICAL STUDENTS AND PHY- SICIAN ASSISTANT TRAINEES}

Preceptors responded to questions geared at what the preceptors expect of the students and what clinical skills they expect students to demonstrate while at their clinical site. The skills are ones that nurse practitioner programs usually expect their students to practice and improve upon in the clinical setting, such as physical examinations, verbal presentations and documentation of clinical findings.

A majority of nurse practitioner and physician preceptors reported that they usually watch students complete a physical examination on at least one patient [NPPs $77 \%$ vs. PPs $68 \%$ ]. Both nurse practitioner and physician preceptors usually have students present patients in SOAP format (Subjective, Objective, Assessment, and Plan) [NPPs 58\% vs. PPs 
78\%]. Approximately $80 \%$ of nurse practitioner and physician preceptors have students verbally present their cases to them and then offer treatment options to the students. See Tables 2a, b, c.

Preceptor respondents compared student nurse practitioners and medical students in the eight (8) clinical skill categories listed in the Methods section and to designate at what medical school year they would consider a beginning student nurse practitioner to be comparable to. More than $50 \%$ of physician preceptors responded that student nurse practitioner students were comparable to first and second year medical students; whereas, more than $50 \%$ of nurse practitioner preceptors compared student nurse practitioners to third and fourth year medical students. In the category of "teaching patients about diagnosis and home care responsibilities", a majority of physician respondents [64\%] stated that NP students compared to third and fourth year medical students. In contrast, $45 \%$ of NP preceptors compared student NPs to $4^{\text {th }}$ year medical students. Findings indicated that a majority of respondents [63\% NPPs vs.87\% PPs] "sometimes or usually" expected better performance skills from medical students than they did from student nurse practitioners. Regarding preceptor expectations of medical students versus student nurse practitioners, a majority of physicians [55\%] stated they are more lenient with student nurse practitioners than with medical students.

Preceptors were also asked if they had experience teaching physician assistant trainees. Eighteen nurse practitioner preceptors and 14 physician preceptors indicated that they did indeed work with physician assistant trainees and responded to items comparing the clinical skills of student nurse practitioners to those of physician assistants. See Table 2d.

\section{CONTENT CLUSTER C}

Preceptor faculty expectations and reasons for precepting student nurse practitioners:

Cluster C addressed preceptors' expectations of what the nurse practitioner program should do for the preceptor, as well as how the preceptor might deal with a student having clinical difficulty.

A high percentage of nurse practitioner preceptors [92\%] and physician preceptors [80\%] expected to talk with faculty or have faculty from the school of origin visit their clinical site during the semester. Eighty-two percent of nurse practitioner preceptors and $66 \%$ of physician preceptors expected faculty to visit the practice site each semester. Regarding preceptor orientation, approximately $80 \%$ of both nurse practitioner and physician preceptors found it helpful for nurse practitioner program to orient the preceptor to what student $\mathrm{s}$ are able to do at the practice site. Forty (40) percent of nurse practitioner preceptors and $57 \%$ of physician preceptors responded that schools have sent students to their practices with little to no information about what the student should do or is able to do at their site.

Table 2a. Preceptor Expectations of Nurse Practitioner Students

\begin{tabular}{|c|c|c|c|c|}
\hline \multirow{2}{*}{$\begin{array}{l}\text { Characterize your expectations for nurse practitioner } \\
\text { students }\end{array}$} & \multirow{2}{*}{ Preceptor Discipline } & \multicolumn{3}{|c|}{ Response } \\
\hline & & $\%$ & $\%$ & $\%$ \\
\hline \multirow{2}{*}{$\begin{array}{l}\text { Question nurse practitioner students by "putting them on } \\
\text { the spot” using direct pointed questions }\end{array}$} & Nurse Practitioner & 32.7 & 57.7 & 9.6 \\
\hline & Physician & 14.3 & 66.7 & 19.0 \\
\hline $\begin{array}{l}\text { Question nurse practitioner students by probing what they } \\
\text { know? }\end{array}$ & Physician & 4.8 & 52.4 & 42.9 \\
\hline \multirow{2}{*}{$\begin{array}{l}\text { Try to determine what nurse practitioner students do not } \\
\text { know? }\end{array}$} & Nurse Practitioner & 15.1 & 39.6 & 45.3 \\
\hline & Physician & 10.0 & 50.0 & 40.0 \\
\hline Give student an assignment to then discuss with you later & Physician & 18.2 & 59.1 & 22.7 \\
\hline \multirow{2}{*}{$\begin{array}{l}\text { Have nurse practitioner student verbally present patient } \\
\text { using SOAP format }\end{array}$} & Nurse Practitioner & 13.5 & 28.8 & 57.7 \\
\hline & Physician & 4.5 & 18.2 & 77.3 \\
\hline \multirow{2}{*}{$\begin{array}{l}\text { Expect nurse practitioner student to present case and offer } \\
\text { treatment options }\end{array}$} & Nurse Practitioner & 0 & 18.9 & 81.1 \\
\hline & Physician & 0 & 18.2 & 81.8 \\
\hline \multirow{2}{*}{$\begin{array}{l}\text { Generally watch a nurse practitioner student complete a } \\
\text { physical examination on at least one patient? }\end{array}$} & Nurse Practitioner & 1.9 & 21.2 & 76.9 \\
\hline & Physician & 13.6 & 18.2 & 68.2 \\
\hline
\end{tabular}


Table 2b. Comparison of Medical Students with Nurse Practitioner Students

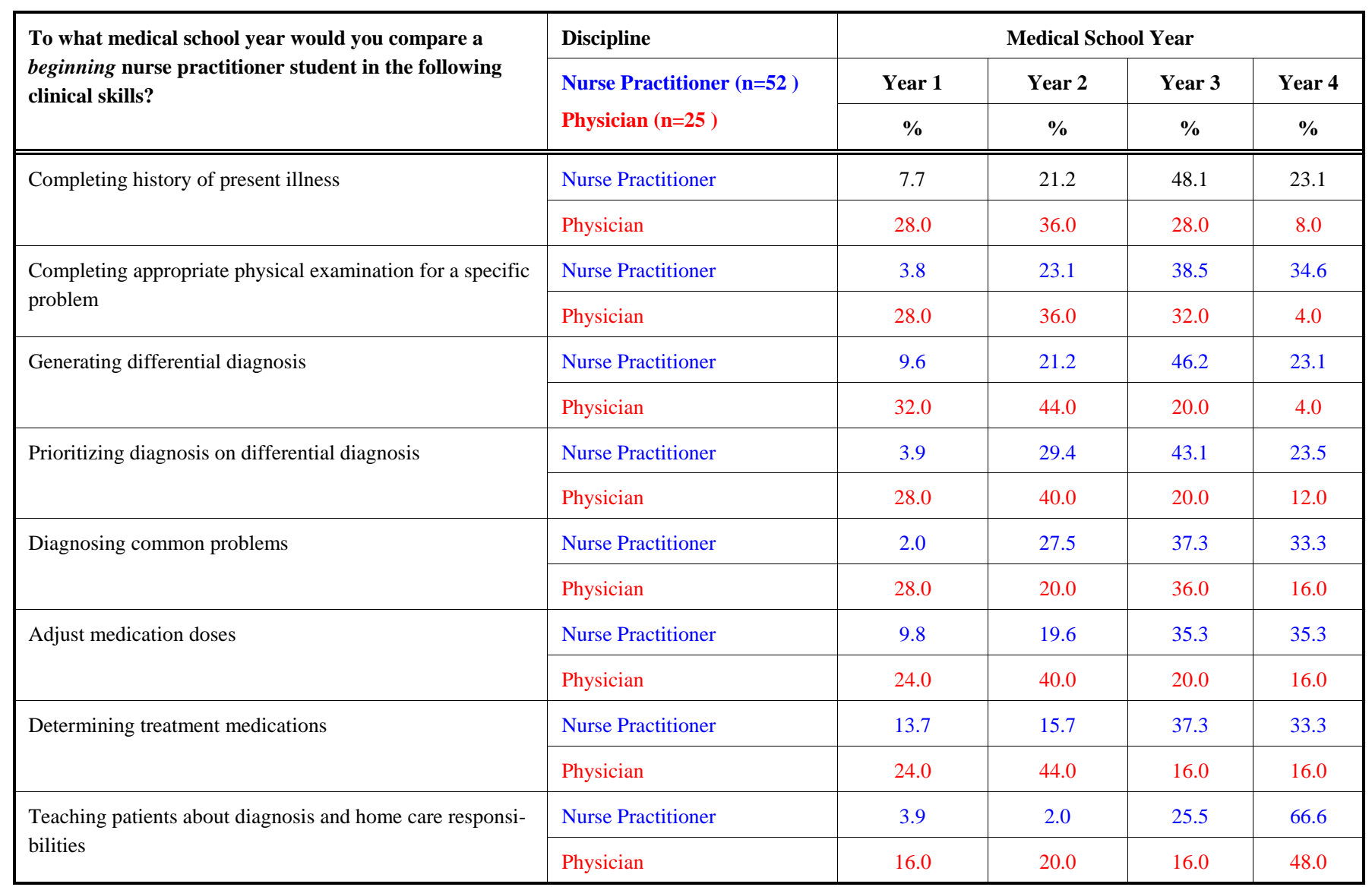

When asked if preceptors find it difficult to tell the student that $\mathrm{s} / \mathrm{he}$ is not meeting their expectations, a majority of nurse practitioner preceptors [66\%] and physician preceptors [52\%] responded that it is difficult to tell students that information. See Table 3a.

Preceptors were also asked to address the reasons they chose to precept student nurse practitioners. The majority of nurse practitioner preceptors (80\%) and physician preceptors (61\%) stated that they precept students because they want to contribute to the professional development of student nurse practitioners. Eighty-four percent of nurse practitioner preceptors and $72 \%$ of physician preceptors enjoy teaching. The survey found that the majority of nurse practitioner and physician preceptors support [NP 83\% vs. PP 78\%] nurse practitioners practicing in primary care. Regarding the role of students in the office setting, $50 \%$ of nurse practitioner preceptors and $46 \%$ of physician preceptors sometimes find that students lend an extra hand in the office, whereas only a low percentage of each group ( $\mathrm{NP}=8 \%$ vs. $\mathrm{PP}=22 \%$ ) responded that students "always" lend an extra hand in the office. See Table $\mathbf{3 b}$.

\section{DISCUSSION AND CONCLUSION}

Nurse practitioner and physician preceptors have many areas of agreement in terms of their expectations of student nurse practitioners. At the beginning of the clinical experience in the primary care setting, nurse practitioner and phy- sician preceptors found student nurse practitioner to be at the expected level of practice these areas:

- completing a history of present illness

- adjusting med doses,

- diagnosing common problems,

- determining treatment medicines and

- teaching about home care responsibilities

Nurse practitioner and physician preceptors responded that the student nurse practitioners were weaker than expected in the areas of generating differential diagnoses and prioritizing differentials. Implications for practice are that the nurse practitioner curriculum can incorporate differential diagnosis in a more intense manner in all courses, including pharmacology, physical examination, and pathophysiology, as well as the nurse practitioner track courses. The theory and practice base of generating and prioritizing differential diagnoses is an area that programs can address in more detail in the theory portion of the curriculum to build up students' skills prior to starting the clinical portion of the track. Including differential diagnosis throughout the nurse practitioner program can help to strengthen a student's understanding of differential diagnoses and increase the comfort level to determine differential diagnoses. Additionally, for the students in their first clinical semester, faculty can address these areas in his/her discussion to enhance clinical skills. 
Table 2c. Expectations of Medical Students Versus Nurse Practitioner Students

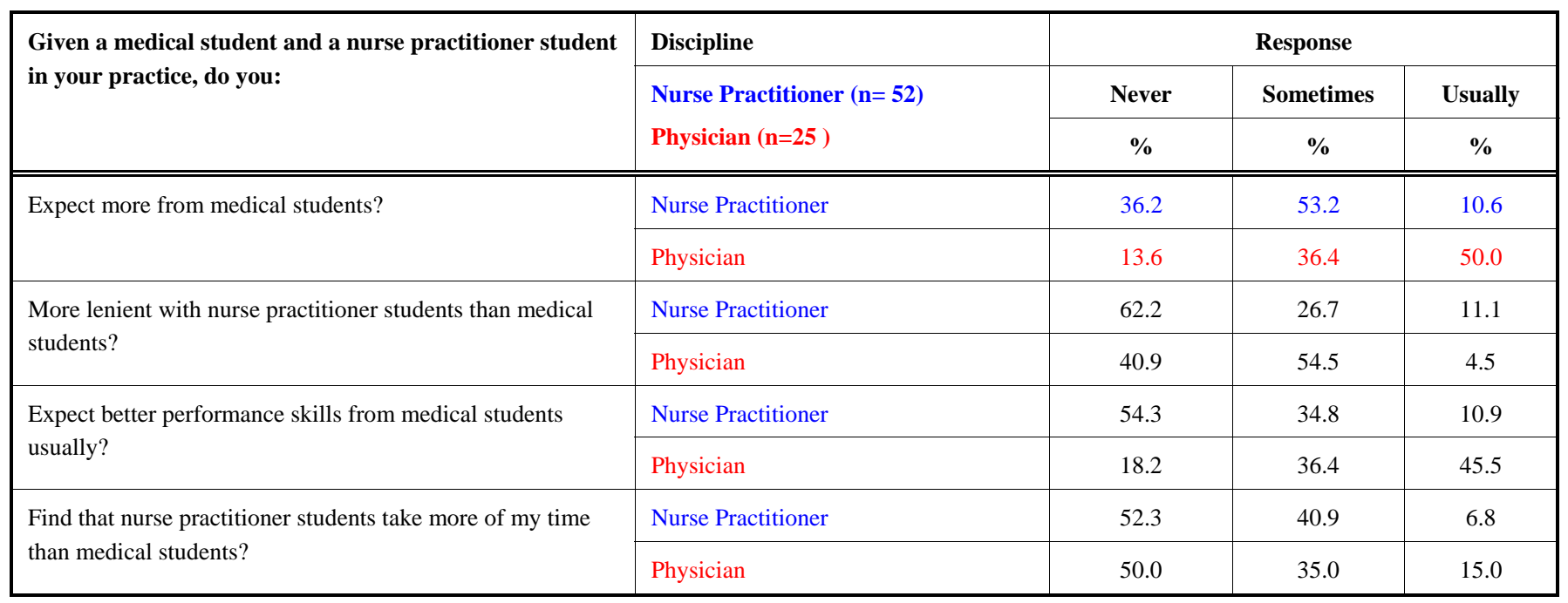

Table 2d. Preceptor Comparison of Nurse Practitioner Students with Physician Assistant Students

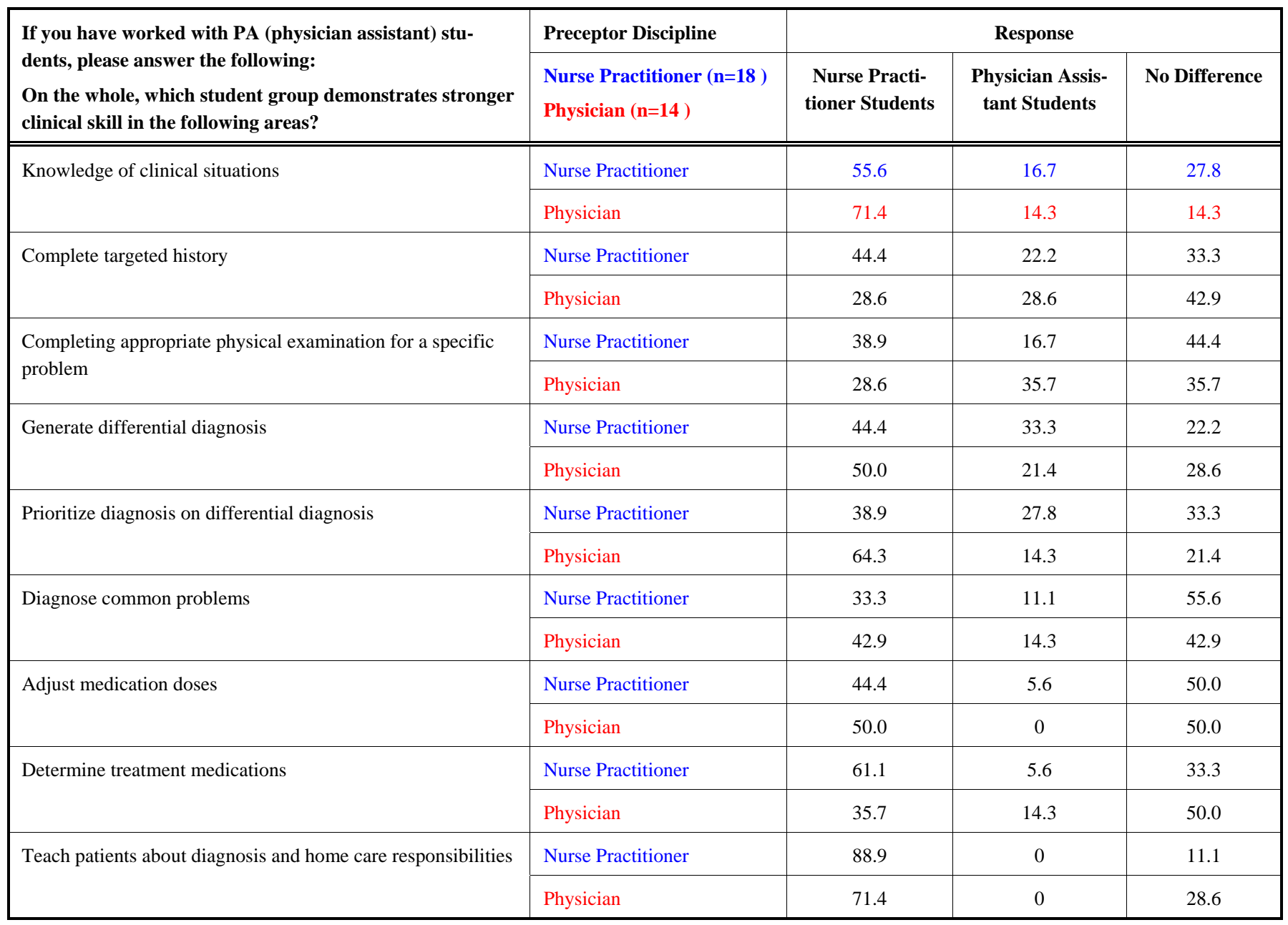

Preceptors indicated that the skill of generating a differential diagnosis is a challenge for student NPs. The theoretical background and thought processes necessary to understand differential diagnoses and prioritizing diagnoses requires continued attention at the content/theory level as well as in the clinical arena. At a practical level, nurse practitioner and physician preceptors might be asked to:

- Reinforce the explicit discussion of the differential diagnosis in the class setting 
Table 3a. Preceptor Expectations of Program

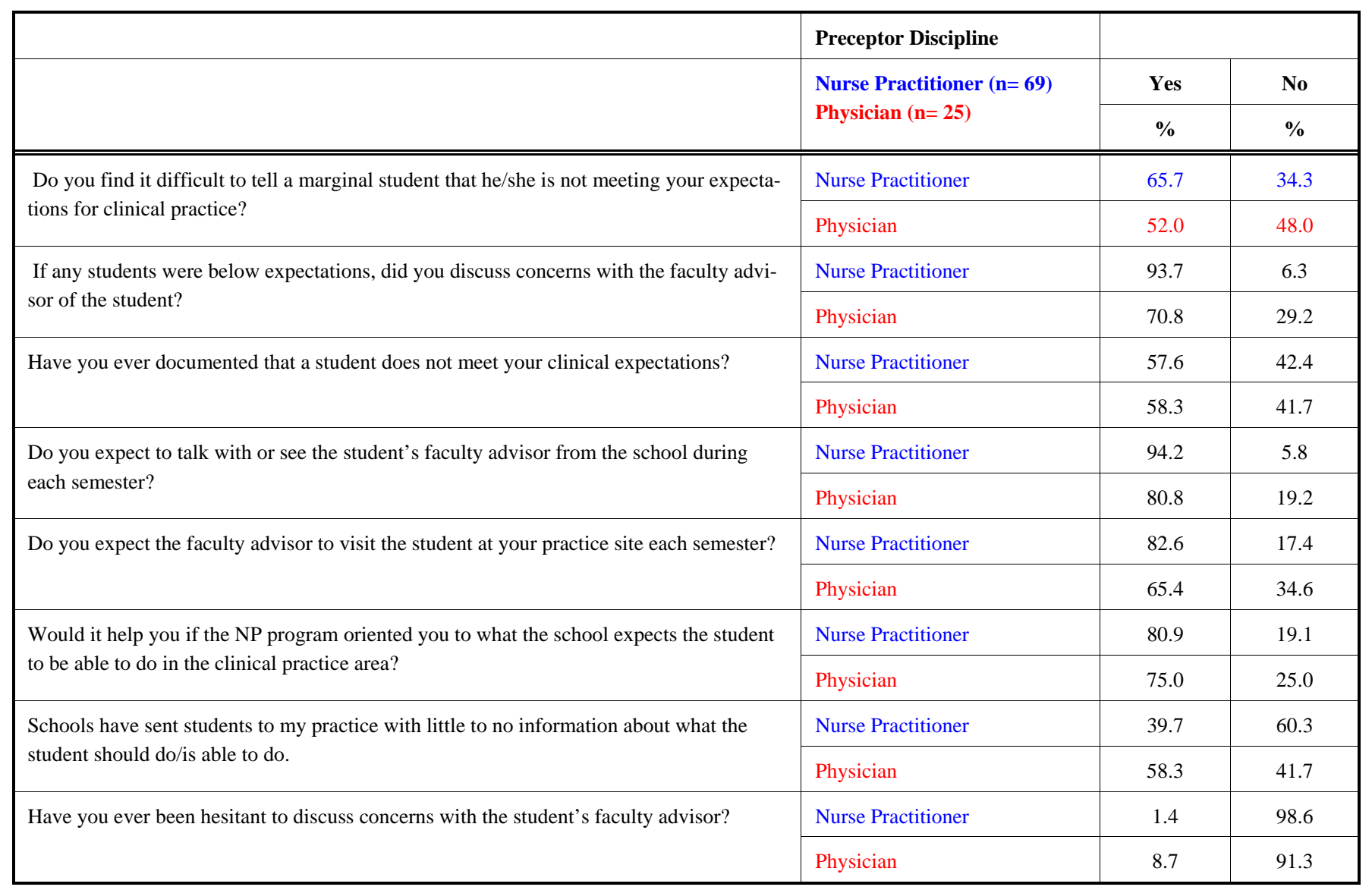

- Increase the focus on student generated differential diagnoses throughout the clinical experience.

Study results show that $75 \%$ of NP preceptors and $68 \%$ of physician preceptors usually watch a student nurse practitioner complete a physical examination on at least one patient. Based on this study's finding, both nurse practitioner and physician preceptors should be encouraged to watch student nurse practitioners perform physical examination on patients at various times throughout the clinical experience in order to directly observe competency to complete an appropriate patient examination. Observing students completing a physical examination on a patient gives preceptors the opportunity to evaluate the student's skills in physical examination and offer feedback to the accuracy of their physical examination skills. Additionally, preceptors should expect and encourage NP students to verbally present patients in a case presentation format to hear the student's evaluation of the history and physical examination completed on the patient.

Nurse practitioner and physician preceptors differed in their comparisons of beginning student nurse practitioners to medical students. In the practice skills of completing a history of present illness (HPI) \& physical examination, adjusting medication doses, generating differentials and prioritizing them, diagnosing common problems and determining treatment medicines, $50 \%$ of nurse practitioner preceptors saw nurse practitioner students as comparable to third and fourth year medical students, whereas more than $50 \%$ of physician preceptors compared student nurse practitioners to first and second year medical students in these specific clinical skills. In contrast, in the more traditional nursing role of patient education skills around_teaching patients about their diagnosis and about home care responsibilities, 64\% of physician preceptors compared student nurse practitioners to third and fourth year medical students.

The study findings indicate that both nurse practitioner and physician preceptors would value knowing the curricular goals and clinical expectations of the student nurse practitioners they precept. Nurse practitioner programs should clearly communicate with the preceptors the program level of the student nurse practitioner. Additionally, the nurse practitioner program should clarify with the preceptor what the student's clinical expectations are at that clinical level. Survey findings showed that most preceptors welcomed and expected program faculty to visit students at the clinical site. Site visits provide an opportunity to offer support and guidance to both nurse practitioner and physician preceptors.

Since study findings showed that more nurse practitioner preceptors than physician preceptors found it difficult to tell a student that $\mathrm{s} /$ he is not doing well. The faculty site visit can serve as an important opportunity to discuss student performance with the preceptors and help them address student problems when necessary. Throughout the clinical experience, the program should make it easy for the preceptors to get support in dealing with student progression and when 
Table 3b. Reasons Preceptors Precept Nurse Practitioner Students

\begin{tabular}{|c|c|c|c|c|c|}
\hline \multirow{2}{*}{ Reasons that you precept NP students? } & \multirow{2}{*}{$\begin{array}{l}\text { Discipline } \\
\text { Nurse Practitioner }(n=69) \\
\text { MD }(n=25)\end{array}$} & Never & Sometimes & Always & Not Answered \\
\hline & & $\%$ & $\%$ & $\%$ & $\%$ \\
\hline \multirow{2}{*}{$\begin{array}{l}\text { Want to contribute to professional development } \\
\text { of nurse practitioners }\end{array}$} & Nurse Practitioner & 0 & 10.1 & 88.4 & 1.4 \\
\hline & MD & 0 & 34.6 & 61.5 & 3.8 \\
\hline Enjoy teaching in general & MD & 0 & 15.4 & 80.8 & 3.8 \\
\hline \multirow[t]{2}{*}{ Students lend an extra hand in the office } & Nurse Practitioner & 42.0 & 49.3 & 7.2 & 1.4 \\
\hline & MD & 30.8 & 46.2 & 19.2 & 3.8 \\
\hline $\begin{array}{l}\text { I support nurse practitioners practicing in pri- } \\
\text { mary care areas }\end{array}$ & Nurse Practitioner & 1.4 & 14.5 & 84.1 & 0 \\
\hline
\end{tabular}

necessary, to determine a collaborative corrective action plan when a student is having clinical difficulty. From a practical standpoint, nurse practitioner programs could provide inservice education to preceptors in order to help them address difficult issues including talking with a student who is having problems in their clinical practice skills.

Like all studies, limitations to this study exist. First, this study was conducted at one institution in the Northeastern region of the US so responses may not represent the perceptions of preceptors in other regions of the country. Secondly, we surveyed a relatively small number of nurse practitioner and physician preceptors although this study did have a solid response rate. Finally, third, the instrument used was developed for this study by the investigators so even though it was pilot tested for clarity; it ideally requires further evaluation to rigorously determine psychometric validation statistics. Despite these limitations, the results appear to be in line with current understanding of how nurse practitioner and physician preceptors approach trainees in the clinical setting.

Finally, the study found that both nurse practitioner and physician preceptors work with student nurse practitioners because they enjoy teaching, want to develop the students professionally, and support nurse practitioners in primary care. It remains important for the nurse practitioner programs to support preceptors through recognition of their willingness to precept and their commitment to foster the next generation of primary care providers. Only a small number of preceptors expressed the view that students lend an extra hand in the office or therefore serve as an additional clinician support, so, the motivation to precept is in fact to help the next generation of providers. It may be helpful for program leaders to acknowledge to preceptors the program's appreciation for the fact that it takes their time and energy to teach and oversee student practice at primary care sites, and to formalize reasonable supports that would be of value to preceptors who invite student nurse practitioners into their office settings.

\section{CONFLICT OF INTEREST}

The authors confirm that this article content has no conflicts of interest.

\section{ACKNOWLEDGEMENT}

The authors express their gratitude to both Dr. Zane Robinson Wolf and the Pennsylvania Higher Education Nursing School Association (PHENSA) for support and encouragement during this research study.

\section{REFERENCES}

[1] Bodenheimer T, Pham H. Primary care: current problems and proposed solutions. Health Aff 2010; 29: 799-805.

[2] Schwartz MD. Health care reform and the primary care workforce bottle neck. J Gen Intern Med 2012; 27(4): 469-72.

[3] Schwartz MD. The US Primary care workforce and graduate medical education policy. JAMA 2012; 308(21): 2252-3.

[4] Burns P, Weatherby Forni P, Moran M, Allen M, Baker C, Booten D. Master's degree nursing education: State of the art. J Prof Nurs 1993; 9: 267-77.

[5] Edmunds M. The nurse preceptor role. Nurse Pract 1993; 6: 52-3.

[6] Hayes E. Helping preceptors mentor the next generation of nurse practitioners. Nurse Pract 1994; 19: 62-6.

[6] Hayes E. Mentoring and nurse practitioner student self-efficacy. Western J Nurs Res 1998(a); 20: 521-35

[7] Hayes E. Mentoring and self-efficacy for advanced nursing practice: a philosophical approach for nurse practitioner preceptors. J Am Acad Nurs Pract 1988; 10: 53-7.

[8] Ligas J. Experiences as preceptor to acute-care nurse practitioner students: one physician's view. AACN Clin issues 1999; 8: 123-31.

[9] Hockenberry-Eaton M, Kline N. Who is mentoring the nurse practitioner. Pediatr Health Care 1995; 9: 94-5.

[10] Davis M, Sawin K, Dunn M. Teaching strategies used by expert nurse practitioner preceptors: A qualitative study. J Am Acad Nurs Pract 1993; 5: 27-33.

[11] Morgan W, Trolinger J. The clinical education of primary care nurse practitioner students. Nurse Pract 1999; 19: 62-6.

[12] Lyon D, Peach J. Primary care provider's views of precepting nurse practitioner students. J Amer Acad Nurs Pract 2001; 13: 237-40.

[13] Brooks MV, Niederhauser VP. Preceptor expectations and issues with nurse practitioner clinical rotations. J Am Acad Nurse Pract 2010; 22(11): 573-9.

[14] Beauchesne M, Howard E. An investigation of the preceptor as potential mentor. Nurse Pract 1996; 21: 155-9. 
[15] Bott, G, Mohide E, Lawlor Y. A clinical teaching technique for nurse preceptors: the five minute preceptor. J Prof Nur 2011;27: 35-42.
[16] Aagaard E, Teherani A, Irby DM. Effectiveness of the one-minute preceptor model for diagnosing the patient and the learner: proof of concept. Acad Med 2004; 79: 42-9.

(C) Giardino and Giardino; Licensee Bentham Open.

This is an open access article licensed under the terms of the Creative Commons Attribution Non-Commercial License (http://creativecommons.org/licenses/by-nc/3.0/) which permits unrestricted, non-commercial use, distribution and reproduction in any medium, provided the work is properly cited. 